Reka Buana : Jurnal Ilmiah Teknik Sipil dan Teknik Kimia, 4(1), 2019, page 1 - 7

Tersedia online di https://jurnal.unitri.ac.id/index.php/rekabuana

ISSN 2503-2682 (Online)

ISSN 2503-3654 (Cetak)

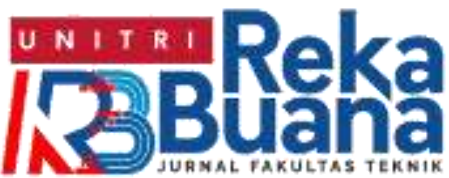

\title{
Pemodelan Hujan Netto Berdasarkan Tutupan Lahan untuk Analisa Debit Aliran Rendah
}

\author{
Adhi Yanuar Avianta 1), Rispiningtati ${ }^{2)}$, Lily Montarcih Limantara ${ }^{3)}$, dan \\ Ery Suhartanto ${ }^{4}$ \\ ${ }^{1}$ Doctoral Program on the Department of Water Resources, Faculty of Engineering, University of \\ Brawijaya, Malang \\ $2,3,4$ Department of Water Resources, Faculty of Engineering, University of Brawijaya, Malang \\ Email : dhidong@yahoo.co.id
}

\begin{abstract}
ABSTRAK
Penelitian ini bermaksud untuk menyelidiki perubahan tutupan lahan dan untuk mendapatkan intersepsi kanopi di DAS Lesti, dan untuk menghasilkan pemodelan curah hujan sebagai fungsi dari faktor curah hujan bersih. Metodologi ini terdiri dari mengidentifikasi tutupan lahan berdasarkan klasifikasi Normalized Difference Vegetation Index (NDVI) dari citra satelit digital Landsat TM 7 dan TM 8, melakukan studi lapangan untuk mendapatkan intersepsi kanopi menggunakan pendekatan keseimbangan volume. Tingkat intersepsi sub-DAS Lesti adalah $5-7 \%$ dalam rata-rata curah hujan, model net-curah hujan sub-DAS Lesti adalah Pnetto $=\mathrm{P}-\left(-1 \mathrm{E} 07 \mathrm{P}^{2}+0,059 \mathrm{P}+0.260\right)$ untuk klasifikasi tanah II dan Pnetto $=$ P $-\left(-1 E 07 P^{2}+0,199 P+0,16\right)$ untuk klasifikasi tanah III, digunakan sebagai input pada pemodelan curah hujan-buangan FJ Mock, hasilnya menunjukkan bahwa penggunaan hujan-bersih pada pemodelan curah hujan-buangan pemodelan FJ Mock meningkat, keakuratan debit yang dihasilkan sangat dipengaruhi oleh proporsi klasifikasi tanah.
\end{abstract}

Kata kunci: intersepsi kanopi; curah hujan bersih; curah hujan-buangan; F.J. Mock

\section{ABSTRACT}

This research intends to investigate the land cover change and to obtain the canopy interception in the Lesti sub-watershed, and to produce the rainfall-discharge modeling as the function of net rainfall factor. The methodology consisted of identifying the land cover based on the Normalized Difference Vegetation Index (NDVI) classification of digital satellite images Landsat TM 7 and TM 8, carrying out the field study to obtain the canopy interception used a volume balance approach. The interception rate of Lesti sub-watershed are $5-7 \%$ in everage of rainfall, the net-rainfall models of Lesti sub-watershed are $P_{\text {netto }}=P-\left(-1 E 07 P^{2}+0.059 P+0.260\right)$ for land clasification II and $P_{\text {netto }}=P-\left(-1 E 07 P^{2}+\right.$ $0.199 P+0.16)$ for land clasification III, it used as the input on the rainfall-discharge modeling of F.J. Mock, the result showed that the use of net-rainfall on the rainfall-discharge modeling of F.J. Mock increased the accuracy of generated discharge which is strongly influenced by the proportional of land classification.

\section{Keywords: canopy interception; net rainfall; rainfall-discharge; F.J. Mock}

\section{PENDAHULUAN}

Intersepsi adalah banyaknya air hujan yang tertangkap oleh tajuk tanaman dan kemudian diuapkan lagi keatmosfer melalui evaporasi dan atau sublimasi. Intersepsi berperan dalam menentukan besarnya hasil air dan aliran permukaan dalam suatu catchment area [1].. Ketika curah hujan yang jatuh telah melebihi kapasitas tamping tajuk pohon (canopy storage capacity), maka lebihan air hujan akan menjadi air lolosan tajuk (throughfall) dan atau mengalir melalui batang 
pohon (stemflow) yang berpotensi menjadi aliran permukaan [2]. Telah banyak hasil penelitian yang memperlihatkan besaran intersepsi, throughfall dan stemflow yang terjadi baik di hutan alam [3, 4, 5]. Besarnya intersepsi berbanding terbalik dengan besarnya intensitas hujan yang turun, pada intensitas hujan yang rendah intersepsi yang terjadi cukup tinggi dan menurun untuk intesitas hujan yang tinggi.

Model hujan-debit FJ. Mock umum dikenal sebagai salah satu model pembangkitan debit untuk debit rendah (low flow mode) namun seringkali memberikan hasil yang kurang memuaskan bila dibandingkan dengan data debit yang tercatat.

Tujuan penelitian ini adalah membuat pemodelan hujan netto berdasarkan tutupan lahan sebagai koreksi input hujan netto pada pemodelan hujan- debit dari FJ. Mock.

\section{METODE PENELITIAN}

Sub DAS Lesti hulu terletak di $8^{\circ} 02^{\prime} 50^{\prime \prime}-8^{\circ} 12^{\prime} 10^{\prime \prime}$ LS dan $112^{\circ} 42^{\prime} 58^{\prime \prime}$ $112^{\circ} 56^{\prime} 21^{\prime \prime}$ BT secara administratif terletak di Kabupaten Malang. Deliniasi Sub DAS Lesti menggunakan peta digital elevation model (DEM) dengan batas hilir di AWLR Tawangrejeni dikecamatan Sumbermanjing Wetan. Lokasi studi seperti pada Gambar 1.

Stasiun penakar curah hujan yang digunakan adalah Stasiun hujan Dampit dan Stasiun hujan Poncokusumo. Luas sub DAS Lesti adalah $395.28 \mathrm{~km}^{2}$. Model hujan netto yang dirancang untuk penelitian ini merupakan korelasi antara curah hujan yang jatuh dengan besarnya intersepsi tajuk. Selisih curah hujan dan besarnya intersepsi tajuk merupakan hujan netto dan dijadikan koreksi input hujan pada model hujan-debit FJ. Mock (1973). Tingkat kerapatan tajuk diidentifikasi dengan Normalized Differences Vegetation Index (NDVI), perubahan luas NDVI dari suatu
Daerah Aliran Sungai (DAS) dipahami sebagai perubahan tataguna lahan dari DAS yang bersangkutan. Analisis yang dilakukan meliputi:

1. Identifikasi tutupan lahan dan klasifikasii NDVI dari sub Daerah Aliran Sungai (DAS) berdasarkan series intepretasi citra Landsat TM dan menguji korelasi tataguna lahan dengan NDVI pada sub DAS

2. Mengadakan penelitian lapangan besaran intersepsi tajuk pada sub DAS Lesti

3. Membuat model hujan netto untuk sub DAS Lesti dan menggunakannya sebagai koreksi input hujan pada model hujandebit FJ Mock (1973)

4. Melakukan kalibrasi dengan debit observasi dari AWLR Tawangrejeni (2000 - 2012) dan validasi koreksi Model FJ Mock Pada sub DAS yang sama untuk tahun berbeda (2013-2017)

\section{Peta NDVI}

Peta kerapatan tutupan tajuk pada sub DAS Lesti dibuat secara seri tahun 2001,2003, 2005,2007 2009 dan 2011 berbasis citra landsat TM 7 dan tahun 2013, 2015 dan 2017 berbasis citra landsat TM 8.

Persamaan yang digunakan untuk menghitung NDVI adalah (Nauri, 2014):

$N D V I=\frac{I R-R}{I R+R}$

Dengan :

IR = nilai reflektansi kanal infra merah (kanal 4)

$\mathrm{R}=$ nilai refleksi kanal merah (kanal 3)

Hasil dari klasifikasi citra satelit NDVI selanjutnya diuji asosiasinya dengan tata guna lahan sub DAS bersangkutan. Untuk nilai penggunaan lahan didapat dari hasil scoring 
berdasarkan penggunaan lahan, nilai pembobotannya sebagai berikut (tabel 1):

a. Skor 3 : hutan (kawasan hutan) klasifikasi lahan III

b. Skor 2 : perkebunan, semak belukar klasifikasi lahan II

c. Skor 1 : Pemukiman, industry, sawah dan tanah kosong, perairan, klasifikasi lahan I

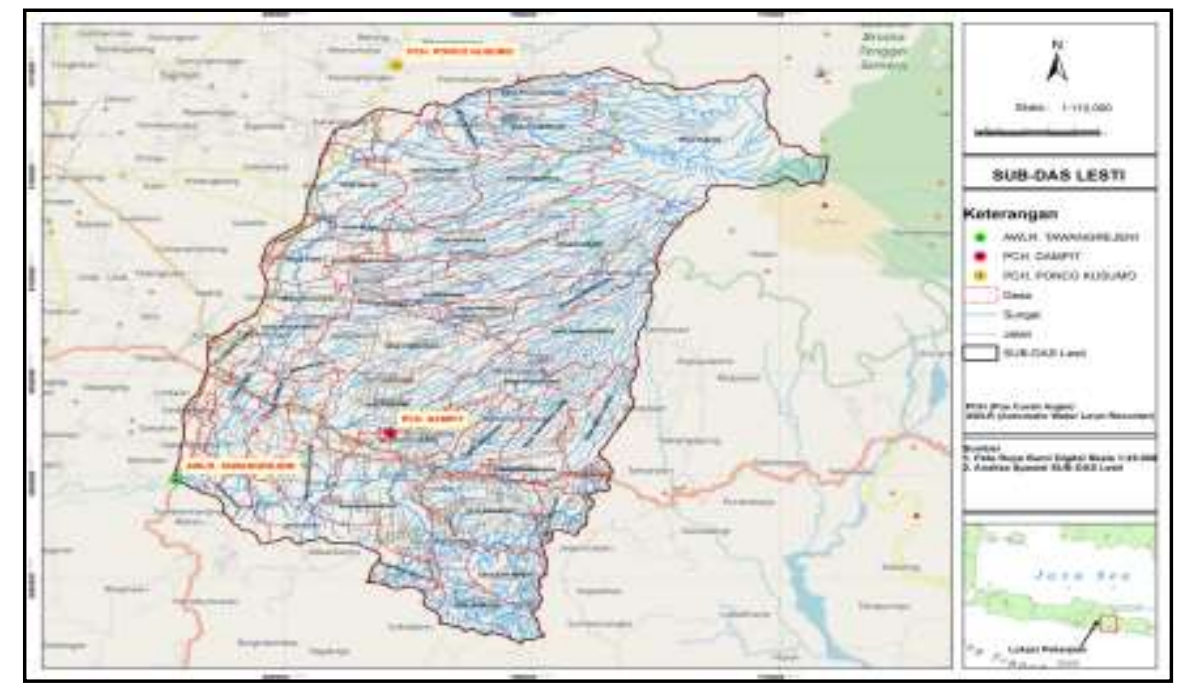

Gambar 1. Peta Sub DAS Lesti, Kabupaten Malang

Tabel 1. Matrik Asosiasi

\begin{tabular}{clcc}
\hline No. & \multicolumn{1}{c}{$\begin{array}{c}\text { Klasifikasi } \\
\text { Peta tataguna lahan }\end{array}$} & Skoring & $\begin{array}{c}\text { Klasivikasi } \\
\text { nilai NDVI }\end{array}$ \\
\hline 1 & Sawah, pemukiman dan semak belukar & 1 & $(\mathrm{j})<0.32$ \\
2 & Perkebunan, ladang dan tegalan & 2 & $0.32 \leq(\mathrm{s})<0.42$ \\
3 & Hutan & 3 & $(\mathrm{r}) \geq 0.42$ \\
\hline
\end{tabular}

Intepretasi mengenai kekuatan hubungan antara dua variable digunakan kriteria ;

$0=$ Tidak ada korelasi antar dua variable, 0 $0.25=$ Korelasi sangat lemah, $0.25-0.5=$ Korelasi cukup, $0.5-0.75=$ Korelasi kuat, $0.75-0.99=$ Korelasi sangat kuat, $1=$ korelasi sempurna (Sarwono,2006). Uji asosiasi kalsifikasi NDVI dengan tataguna lahan menggunakan uji $t$ pada sampel berpasangan (t-test paired sample).

\section{HASIL DAN PEMBAHASAN}

Dengan menggunakan peta klasifikasi NDVI yang telah dijastifikasi, dibuat grafik rasio perubahan penggunaan lahan sebagaimana Gambar 2. Hasil rasionalisasi seperti pada Gambar 2. Pergeseran rasio luasan lahan dengan klasifikasi I : penggunaan lahan untuk pemukinan, industri, sawah, ladang, dan tanah kosong, menunjukan pergeseran (meluas) selama 16 tahun sebesar $12 \%$ dan untuk klasifikasi III : hutan, rasio luasan bergeser (menyempit) sebesar $8 \%$, ini menunjukan telah terjadi perubahan tataguna lahan di sub DAS Lesti. Untuk klasifikasi II : Perkebunan dan semak belukar, nampak rasio luasan tidak menunjukan trend kecenderungan, bergerak antara 35 - $29 \%$. Korelasi nilai NDVI dengan tataguna lahan sebesar 0.77 menunjukan korelasi yang sangat kuat. 


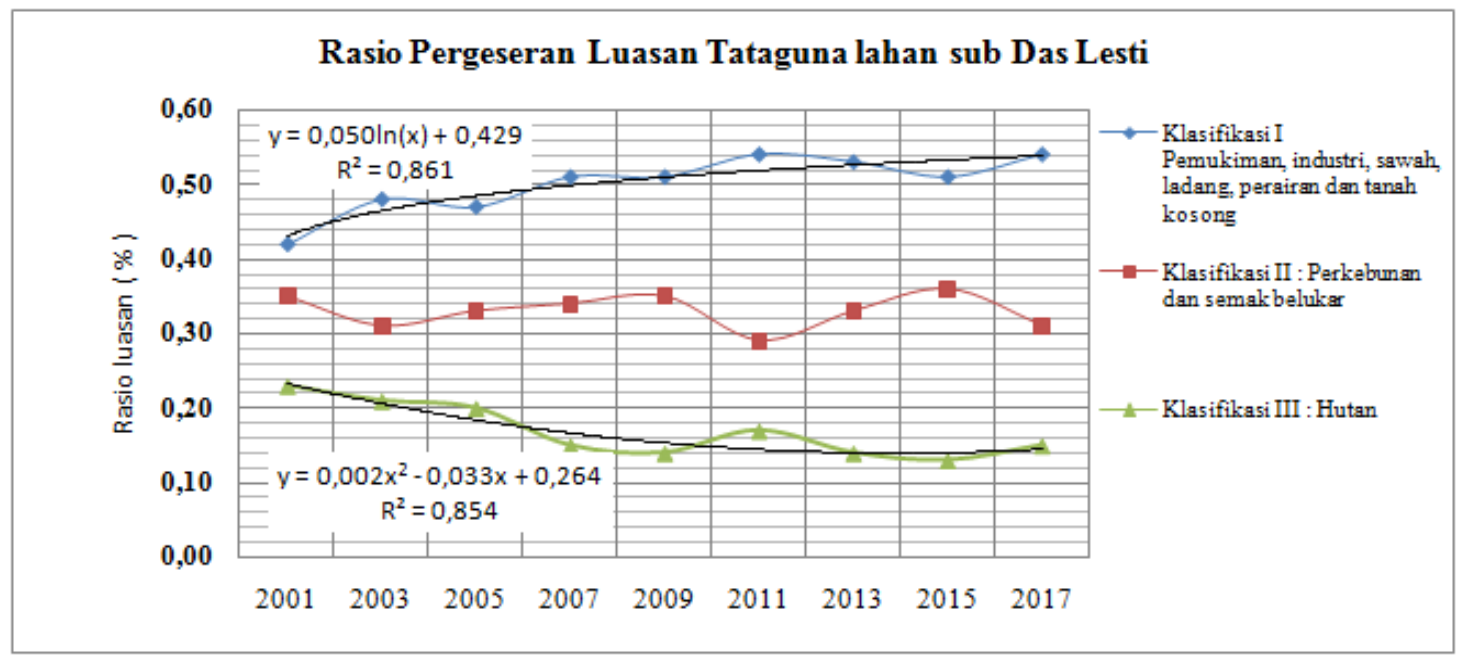

Gambar 2. Grafik Rasio Pergeseran Luasan Tataguna Lahan

\subsection{Intersepsi tajuk}

Pengukuran intersepsi hanya dilakukan pada lahan klasifikasi II (3 stasiun) dan lahan klasifikasi III (2 stasiun) dengan metode acak bertingkat (stratified random sampling). Data kemudian dikompilasi menjadi satu seri data untuk klasifikasi lahan II dan untuk klasifikasi lahan III menghasilkan hubungan antara curah hujan dan besarnya intersepsi untuk masingmasing klasifikasi lahan (Gambar 3).

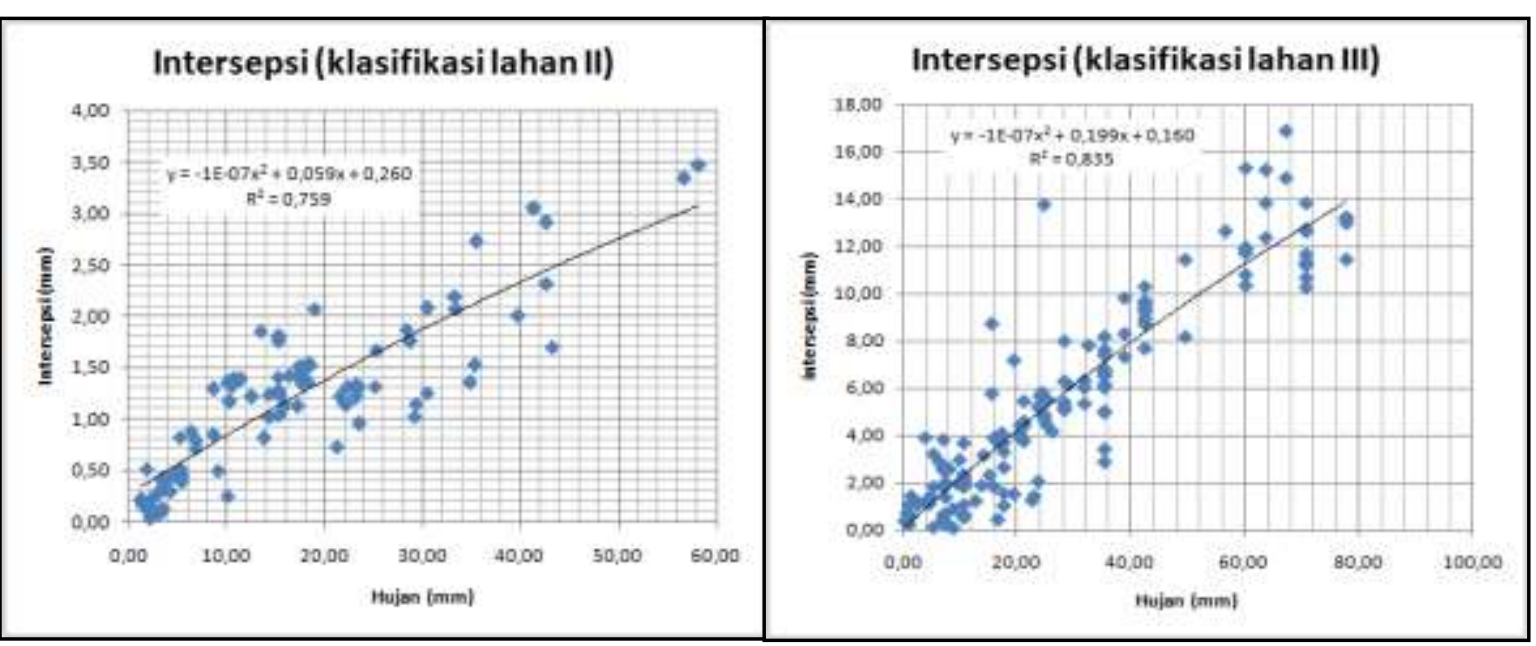

Gambar 3. Intersepsi Klasifikasi Lahan

\subsection{Permodelan hujan netto}

Model hujan netto dibuat menggunakan persamaan

$C h_{\text {net }}=C h_{\text {gross }}-I$

\section{Keterangan :}

$\mathrm{Ch}_{\text {net }}=$ curah hujan bersih ( $\left.\mathrm{mm}\right)$

$\mathrm{Ch}_{\text {gross }}=$ curah hujan $(\mathrm{mm})$

$\mathrm{I}=$ intersepsi tajuk $(\mathrm{mm})$ 
* Model hujan netto untuk klasifikasi lahan II sub DAS Lesti

$\mathrm{P}_{\text {netto }} \quad=\mathrm{P}-\left(-1 \mathrm{E} 07 \mathrm{P}^{2}+0.059 \mathrm{P}+0.260\right)$

Dengan:

$\mathrm{P}_{\text {netto }} \quad=$ Hujan setelah intersepsi $(\mathrm{mm})$

$\mathrm{P} \quad=$ Hujan yang tercatat di stasiun hujan $(\mathrm{mm})$

Catatan : untuk curah hujan $(\mathrm{P}) \leq 3 \mathrm{~mm}$ maka $\mathrm{P}_{\text {netto }}=0.85^{*} \mathrm{P}$

untuk curah hujan $(\mathrm{P})>70 \mathrm{~mm}$ maka $\mathrm{P}_{\text {netto }}=0.94 * \mathrm{P}$

Model hujan netto untuk klasifikasi lahan III sub DAS Lesti

$\mathrm{P}_{\text {netto }} \quad=\mathrm{P}-\left(-1 \mathrm{E} 07 \mathrm{P}^{2}+0.199 \mathrm{P}+0.16\right)$

Dengan:

$\mathrm{P}_{\text {netto }} \quad=$ Hujan setelah intersepsi $(\mathrm{mm})$

$\mathrm{P} \quad=$ Hujan yang tercatat di stasiun hujan $(\mathrm{mm})$

Catatan : untuk curah hujan $(\mathrm{P}) \leq 3 \mathrm{~mm}$ maka $\mathrm{P}_{\text {netto }}=0.70 * \mathrm{P}$

untuk curah hujan $(\mathrm{P})>70 \mathrm{~mm}$ maka $\mathrm{P}_{\text {netto }}=0.86 * \mathrm{P}$

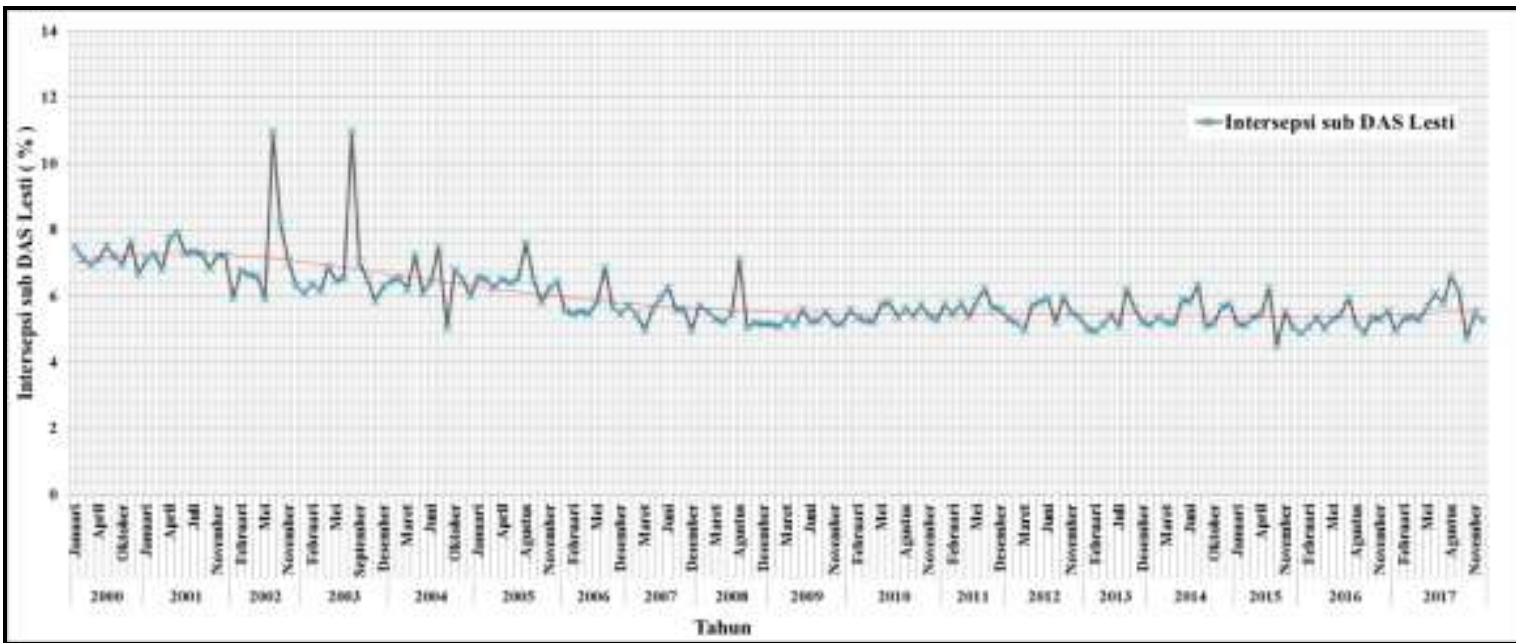

Gambar 4. Pergerakan Besaran Intersepsi Sub DAS Lesti

Gambar 4 menunjukan pergerakan besaran intersepsi di sub DAS Lesti, garis merah merupakan nilai tengah intersepsi daerah yang menunjukan kecenderungan menurun, hal ini berkorelasi dengan berkurangnya rasio luasan lahan dengan klasifikasi III di sub DAS lesti.

\subsection{Simulasi hujan-debit FJ Mock}

Pemodelan hujan-debit FJ Mock (1973) dengan 2 (dua) kondisi yaitu: simulasi tanpa intersepsi tajuk dan dengan intersepsi tajuk, simulasi dilakukan dimulai dari bulan Januari tahun 2000 sampai bulan Desember tahun 2012. Kalibrasi dilakukan dengan optimasi menggunakan "SOLVER" menunjukan bahwa dengan mengkoreksi data hujan dengan model hujan netto pada simulasi hujan-debit FJ Mock pada sub DAS Lesti memberikan hasil yang lebih baik, pada tabel 4 indikator statistik menunjukkan bahwa dengan intersepsi menunjukan angka lebih baik bila dibandingkan tanpa intersepsi.

Validasi model dilakukan menggunakan parameter FJ Mock hasil kalibrasi tanpa dilakukan optimasi memberikan hasil memuaskan sebagaimana tampak pada Gambar 7. dan Tabel 5. 


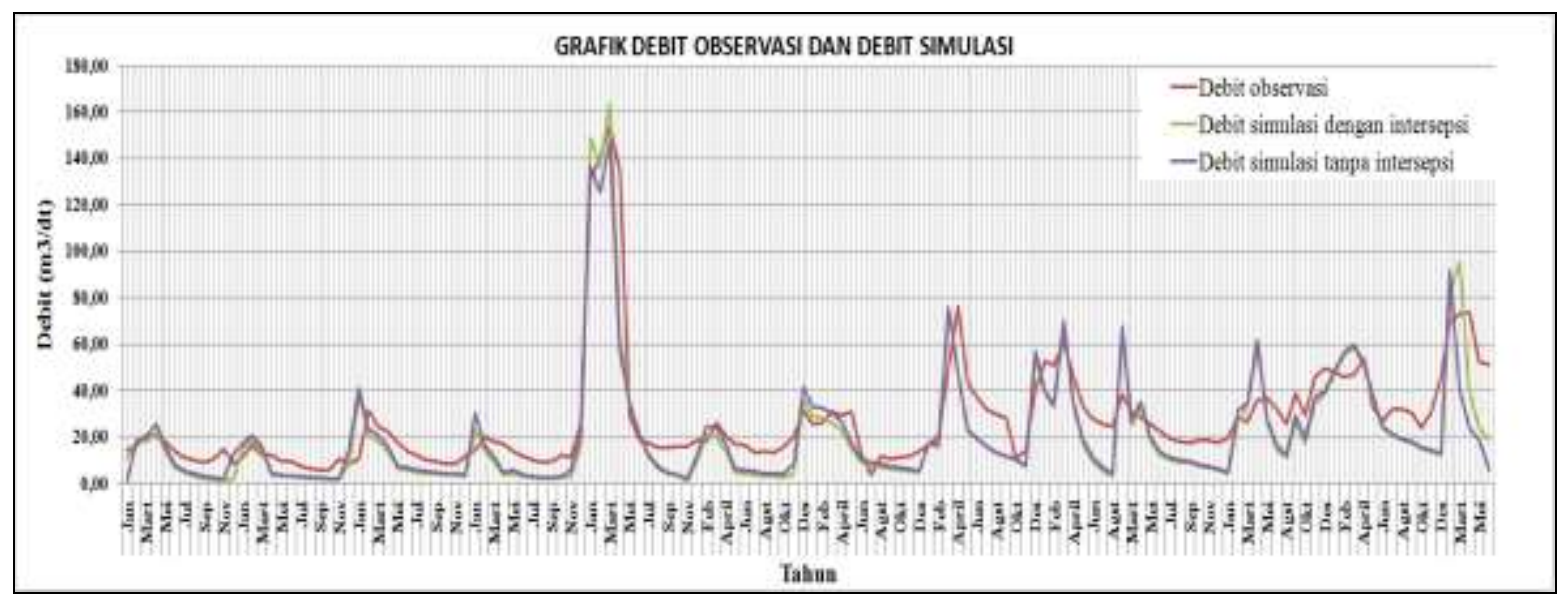

Gambar 5. Grafik Simulasi Hujan-Debit Sub DAS Lesti

Tabel 4. Indikator Statistik

\begin{tabular}{lccc}
\hline \multicolumn{1}{c}{ Ketelitian hasil simulasi } & Tanpa intersepsi & Dengan intersepsi & Ket. \\
\hline Nash Sutch-liffe (NSE) & 0.63 & 0.64 & $0.36<\mathrm{NSE}<0.75$ \\
Koefisien korelasi PEARSON & 0.85 & 0.97 & $0.7<\mathrm{R}<1$ \\
Root mean square error (RMSE) & 14.70 & 14.53 & $\approx 1$ \\
Mean error (ME) & 5.15 & 6.15 & + atau - \\
Rasio limpasan Rl & 0.77 & 0.78 & $\approx 1$ \\
\hline
\end{tabular}

Tabel 5. Indikator Statistik

\begin{tabular}{lcc}
\hline \multicolumn{1}{c}{ Ketelitian hasil simulasi } & Ketelitian & Ket. \\
\hline Nash Sutch-liffe (NSE) & 0.37 & $0.36<\mathrm{NSE}<0.75$ \\
Koefisien korelasi PEARSON & 0.98 & $0.7<\mathrm{R}<1$ \\
Root mean square error (RMSE) & 11.34 & $\approx 1$ \\
Mean error (ME) & 7.47 & + atau - \\
Rasio limpasan Rl & 0.71 & $\approx 1$ \\
\hline
\end{tabular}

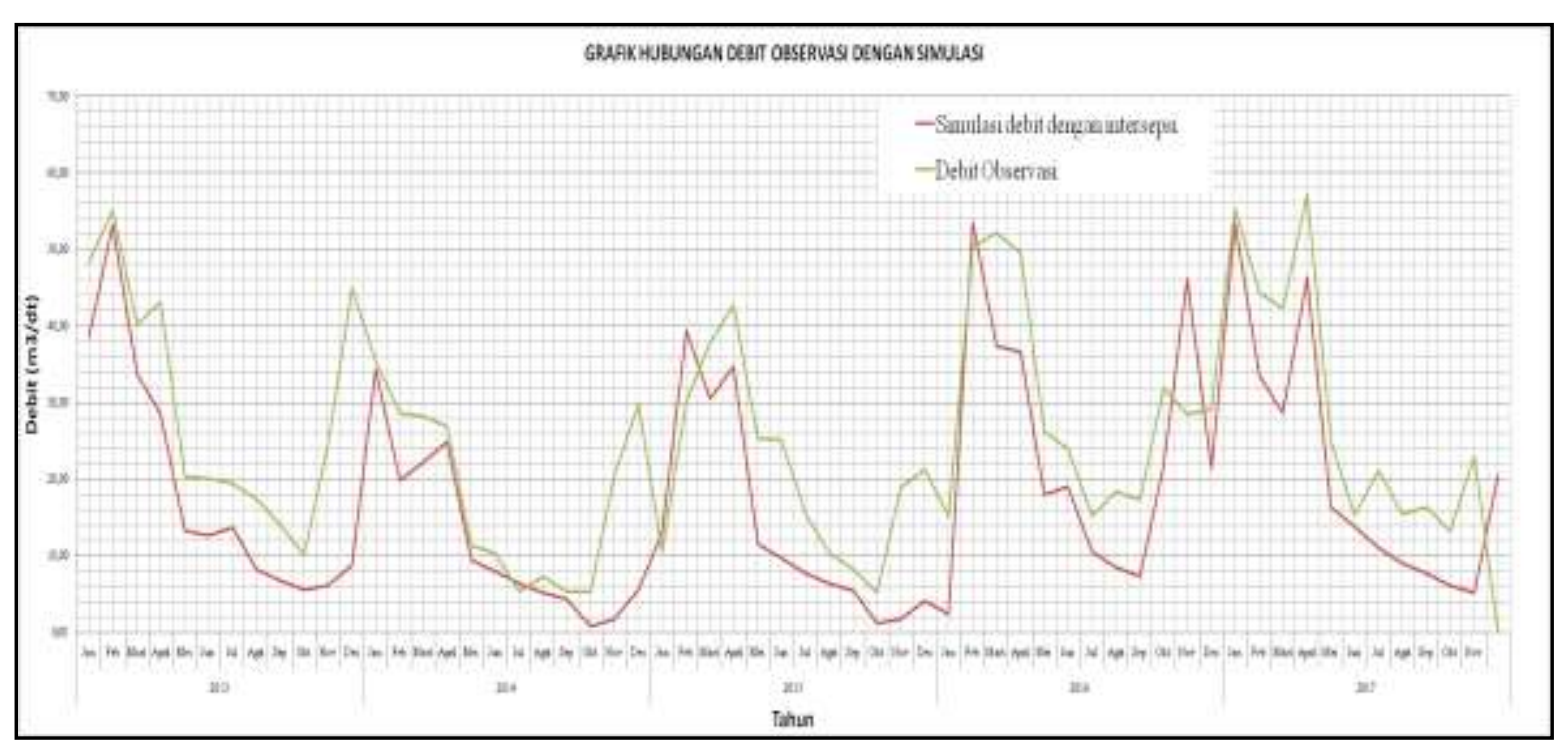

Gambar 6. Grafik Debit Obsevasi dan Debit Simulasi (Validasi) 


\section{KESIMPULAN}

Kesimpulan yang didapat dari penelitian ini adalah telah terjadi perubahan tataguna lahan di sub DAS Lesti. Penggunaan model hujan netto pada model hujan-debit FJ Mock dapat meningkatkan akurasi debit yang dibangkitkan. Peningkatan akurasi dari

\section{DAFTAR PUSTAKA}

[1]. Schellekens, J. (2000). The interception and runoff generation processes in Bisley catchment, Luquillo Experimental Forest, Puerto Rico. Physical Chemistry Earth (B) 25(7-8): 659-664.

[2]. Bruijnzeel, L.A. (1990). Hydrology of moist tropical forest and effects of conversion:A stage of knowledge review. UNESCO International Hydrological Programme \& Free University, Amsterdam

[3]. Herwitz, R.S. dan Slye, R.E. (1992). Spatial Variability In The Interception Of Inclined Rainforest By a Tropical Rainforest Canopy. Selbyana 13: 6271. pembangkitan debit sangat dipengaruhi oleh proporsi klasifikasi lahan. Koefisien model FJ Mock untuk sub DAS Lesti adalah koefisien infiltrasi 0.5 , koefisien resesi aliran tanah 0.82 , koefisien hujan lebat 3.49, dan koefisien debit 1.95.

[4]. Asdak, C., Jarvis, P.G., Van Gardingen, P. dan Fraser, A. (1998). Rainfall interception loss in unlogged and logged forest areas of Central Kalimantan, Indonesia. J. Hydrology 206: 237-244.

[5]. Klinge, R., Schmidt, J. dan Folster, H. (2001). Simulation of water drainage of a rain forest and forest conversion plots using a soil water model. Journal of Hydrology 246: 82-95. 